\title{
Clinical significance of microRNA-24 expression in esophageal squamous cell carcinoma
}

\author{
W. DONG ${ }^{1,2}$, B. LI' ${ }^{2, *}$, Z. WANG ${ }^{1,2}$, Z. ZHANG ${ }^{2}$, J. WANG ${ }^{2}$ \\ ${ }^{1}$ Department of Radiation Oncology, Cancer Hospital, Tianjin Medical University, Tianjin, China; ${ }^{2}$ Department of Radiation Oncology, Shandong \\ Cancer Hospital, Jinan, China
}

*Correspondence: baoshli1963@163.com

Received April 12, 2014 / Accepted June 2, 2014

\begin{abstract}
microRNA-24 has been reported to participate in tumorgenesis and progression by several signaling pathways in various tumors. However, its potential as a serum diagnostic factor and predictive biomarker for esophageal squamous cell carcinoma (ESCC) has not been studied. In the present study, serum samples were collected from 105 pathologically proven ESCC patients and 30 healthy volunteers. All patients were treated with concurrent chemotherapy and radiotherapy. Real-time polymerase chain reaction was carried out to measure the serum miR-24 expression level in all patients and volunteers. The data were compared among radio-sensitive group $(\mathrm{CR}+\mathrm{PR}, 62$ patients), radio-resistant group ( $\mathrm{SD}+\mathrm{PD}, 43$ patients) and healthy volunteers to elucidate the diagnostic value of serum miR-24 testing for ESCC and the predictive value of miR-24 expression of treatment response. In the result, of the 105 ESCC patients enrolled in the study, 62 patients achieved partial or complete response. The serum miR-24 level in ESCC patients is 4.82 times as high as that in healthy subjects $(\mathrm{P}<0.01)$, indicating that serum miR-24 expression could be an excellent diagnostic factor. The mean miR-24 serum levels differ by 2.05 folds between radiosensitive group and radioresistant group, indicating that it may serve as a biomarker for predicting the response of ESCC patient to CRT. Furthermore, the responsiveness of therapy is significantly correlated with Cyfra21$1(\mathrm{P}<0.05)$, serum miR-24 level $(\mathrm{P}<0.05)$ and the myelosuppression $(\mathrm{P}<0.01)$. In the prsent study, we come to the conclusion that serum miR-24 has the potential to serve as a noninvasive biomarker for both ESCC diagnosis and predicting treatment responses to concurrent chemo-radiation therapy. ESCC patients with lower Cyfra21-1, higher miR-24, and severer myelosupression were much more sensitive to CRT.
\end{abstract}

Key words: miR-24 expression, esophageal squamous cell carcinoma, chemo-radiation therapy, radiosensitivity

Esophageal cancer (EC) is the sixth most common cancer and the fifth leading cause of cancer death in men worldwide, there was an estimated 482,300 new EC cases and 406,800 EC-caused deaths in 2008 worldwide [1]. Despite improved treatments in recent years, curative surgical resection, which is initially recommend for early stage cases, feasible for only $30-40 \%$ of patients [2]. While the outcome of surgery for patients with such an aggressive tumor has been unsatisfactory, with a 5-year survival rate less than $20 \%$ [3].

Prognostic assessment is critical for making better therapeutic choices for ESCC patients, and the tumor-nodemetastasis (TNM) staging system is the key prognostic determinant. However, the variations in clinical responses to CRT are most evident for esophageal squamous cell carcinoma (ESCC), and the survival rates between responders and non-responders are quite different even in the same clinical stage $[4,5]$. Rapidly increasing findings on cancer biology provide prognostic information that complements and, in some cases, is more relevant than anatomical extent [6]. The discovery and application of molecular biomarkers that can be incorporated into the cancer staging system could improve the accuracy of prognostic prediction [7]. Therefore, there is a compelling need to identify novel biomarkers that hold the promise of precisely predicting tumor response to CRT to tailor treatments for different ESCC patients and enhance survival [8].

MicroRNAs (miRNAs) are single-tranded RNA molecules of approximately 21-23 nucleotides in length, which negatively regulate the translation of coding $\mathrm{mRNAs}$ in a sequence-specific manner[9]. MiRNA expression profiling is of increasing importance as a useful diagnostic and prognostic tool, and many studies have indicated that miRNAs act as either an 
oncogene or a tumor suppressor[10,11]. The researches and knowledge on the microRNA dysfunction and tumorigenesis, development and prognosis continue to grow [12-15]. Specific miRNAs that strongly affect the progression of human tumors and the prognosis of the patients have been identified in different cancers, suggesting that miRNAs may be used as a potential therapeutic avenue for cancer treatment[16]. Furthermore, it has been shown that miRNAs are present in human serum or plasma in a remarkably stable form that is protected from endogenous RNase activity, which highlights the potential of circulating miRNAs to act as stable blood-based markers for the detection of cancer or other human diseases[17-19].

Like most miRNAs, miR-24 functions in many other biological processes and pathways[20]. MiR-24 was first reported to negatively regulate erythroid differentiation through inhibition of human activin type I receptor ALK4 [21]. In addition, miR-24 appears to inhibit the tumor suppressor p16 [22], reduce the DNA repair ability[23], inhibit cell cycle progression [24], suppress apoptosis [20], and is positively connected with hypoxia [25]. Hypoxia is an essential feature of the tumor microenvironment, while on the other hand, tumor radiosensitivity is influenced by hypoxia and angiogenesis, which are two factors that determine whether cancer cells are radiosensitive. Although dysregulation of miR-24 has been found in a variety of cancers, including oral carcinoma [26], lung cancer [27], retinoblastoma [28], colorectal cancer[29]. However, the relationship of miR-24 to esophageal squamous cell carcinoma is still unclear up to now. In view of these literatures, we focused on the serum miR-24 expression in patients with ESCC. The aim of current study is to understand the association between serum miR-24 expression and clinical response of ESCC to CRT and evaluate the possibility of using serum miR-24 as a diagnostic and predicting factor for ESCC.

\section{Patients and methods}

Ethics statement. Serum-based specimen collection and studies were approved by the institutional review boards of Shandong Cancer Hospital, Shandong Academy of Medical Sciences. All participants provided written consent and indicated willingness to donate their blood samples for research.

Patients and serum samples. Serum samples were collected from the peripheral venous blood of 105 patients and 30 healthy volunteers at the Department of Radiation Oncology, Shandong Cancer Hospital. Clinical data of enrolled patients including sex, age, tumor locations, status of lymph node metastasis, distant metastasis, the maximum diameter of tumor, and tumor differentiation were recorded. Entry criteria for this study were: (a) pathologically proven ESCC, (b) no previous treatment, (c) Karnofsky performance status (KPS) scale 70-100, (d) normal bone marrow, liver, and renal function, (e) patients without severe complications, (f) patients have computed tomography $(\mathrm{CT})$ and barium swallow examinations (pre- and post-treatment), and (g) informed consents were obtained before treatment. All patients were given the same regimen of CRT. In addition, thirty healthy controls, who came to Shandong Tumor Hospital for physical examination during the period from October 2012 to April 2013, were diagnosed without any tumor.

The blood samples were centrifuged at 3,000 rpm for $10 \mathrm{~min}$, and then the serum was stored at $-80^{\circ} \mathrm{C}$. Repeated freeze-thawing was avoided during storage to ensure the quality of the samples. Two months after the completion of concurrent CRT, an objective evaluation was made according to the Response Evaluation Criteria In Solid Tumors (RECIST) guidelines recommended by the World Health Organization[30]: each patient's response was defined as complete remission (CR), partial remission (PR), stable disease (SD) or progressive disease (PD).

Treatment schedule. The treatment comprised two sources of protracted 5-fluorouracil (5-FU) infusion $\left(400 \mathrm{mg} / \mathrm{m}^{2}\right.$ daily on days $1-5$ and 8-12) and a 2 hours infusion of cisplatin ( $40 \mathrm{mg} / \mathrm{m}^{2}$ on days 1 and 8 ) combined with radiation therapy. Radiation therapy was administered using conformal radiotherapy or intensity modulated radiotherapy with $15-\mathrm{MV}$ $\mathrm{X}$-rays in 34 fractions with total doses of $59.6 \mathrm{~Gy}$ (first phase, 40 Gy/20f/2 Gy; second phase, 19.6 Gy/14f/1.4 Gy twice a day with an interval of at least 6 hours between treatments).

RNA extraction. Total RNA, including miRNAs, was extracted from 400ul of serum using the mirVana PARIS RNA isolation kit (Ambion, Austin, TX, USA) according to the manufacturer's instructions. In addition, $25 \mathrm{fmol}$ of a synthetic Caenorhabditis elegans miRNA, cel-miR-39 (Sangon Biotech, Shanghai, China), was added to $400 \mu \mathrm{l}$ serum after addition of the lysis buffer; the spike-in of a synthetic miRNA allowed us to control the variations between sample-to-sample. The purity and concentration of RNA were determined using a dual-beam ultraviolet spectrophotometer (ASP3700, ACTGene, USA). Briefly, 400ul of serum was added to the precipitate, an equal volume of $2 \times$ denaturing solution was added and mixed sufficiently before being mixed with an equal total volume of acidphenol:chloroform. A mirVana miRNA column was used to collect total RNA. The bound RNA was cleaned with the buffers provided by the manufacturer to remove impurities and eluted in a final volume of $50 \mu \mathrm{l}$.

Screening and verification of circulating miRNAs by RTPCR. MicroRNA cDNA was created by reverse-transcribed using the TaqMan MicroRNA Reverse Transcription Kit (Applied Biosystems, San Diego, CA, USA) according to manufacturer's instructions. Briefly, a total reaction volume of $15 \mu \mathrm{l}$ containing $5 \mu \mathrm{l}$ of RNAs, $0.15 \mu \mathrm{l}$ of $100 \mathrm{mM}$ deoxyribonucleotide triphosphate, $1 \mu \mathrm{l}$ of multiscribe reverse transcriptase $(50 \mathrm{U} / \mu \mathrm{l}), 1.5 \mu \mathrm{l}$ of $10 \times$ reverse transcription buffer, and $0.19 \mu \mathrm{l}$ of RNase inhibitor $(20 \mathrm{U} / \mu \mathrm{l}), 4.16 \mu \mathrm{l}$ of RNase-free water and $3 \mu \mathrm{l}$ of $5 \times \mathrm{RT}$ primer. The $15 \mu \mathrm{L}$ RT reactions were incubated for $30 \mathrm{~min}$ at $16^{\circ} \mathrm{C}, 30 \mathrm{~min}$ at $42^{\circ} \mathrm{C}, 5 \mathrm{~min}$ at $85^{\circ} \mathrm{C}$, and then maintained at $4^{\circ} \mathrm{C}$. Real-time polymerase chain reaction (RT-PCR) was carried out on the ABI 7900 Real-Time PCR System (Applied Biosystems, San Diego, CA, 
USA). A total of $20 \mu \mathrm{l}$ PCR reaction included $1 \mu \mathrm{l} 20 \times$ TaqMan MicroRNA Assay, $1.33 \mu \mathrm{l}$ RT product, $10 \mu \mathrm{l}$ of TaqMan $2 \times$ Universal PCR Master Mix, and $7.67 \mu \mathrm{l}$ of RNase-free water. The reactions were incubated in a 384-well optical plate for

Table 1. Clinicopathological features of 105 patients with ESCC

\begin{tabular}{|c|c|c|c|}
\hline \multirow{2}{*}{ Characteristics } & & \multicolumn{2}{|r|}{ Patients } \\
\hline & & No & Constituent ratio(\%) \\
\hline \multicolumn{4}{|l|}{ Sex } \\
\hline & Male & 69 & 65.7 \\
\hline & Female & 36 & 34.3 \\
\hline \multicolumn{4}{|l|}{ Age } \\
\hline & $\geqq 60$ & 72 & 68.6 \\
\hline & $<60$ & 33 & 31.4 \\
\hline \multicolumn{4}{|l|}{ Tumor location } \\
\hline & Upper third & 30 & 28.6 \\
\hline & Middle third & 60 & 57.1 \\
\hline & Lower third & 15 & 14.3 \\
\hline \multicolumn{4}{|l|}{ Length } \\
\hline & $\leqq 4.0$ & 53 & 50.5 \\
\hline & $4.1-6.0$ & 32 & 30.5 \\
\hline & $>6.0$ & 20 & 19.0 \\
\hline \multicolumn{4}{|l|}{ Differentiation } \\
\hline & High & 24 & 22.9 \\
\hline & Moderate & 54 & 51.4 \\
\hline & Poor & 27 & 25.7 \\
\hline \multicolumn{4}{|c|}{ Lymph Node Metastasis } \\
\hline & Positive & 53 & 50.5 \\
\hline & Negative & 52 & 49.5 \\
\hline \multicolumn{4}{|c|}{ Distant Metastasis } \\
\hline & Positive & 25 & 23.8 \\
\hline & Negative & 80 & 76.2 \\
\hline \multicolumn{4}{|l|}{ Smoking History } \\
\hline & Positive & 50 & 47.6 \\
\hline & Negative & 55 & 52.4 \\
\hline \multicolumn{4}{|l|}{ Drinking history } \\
\hline & Positive & 40 & 38.1 \\
\hline & Negative & 65 & 61.9 \\
\hline \multicolumn{4}{|l|}{ Family history } \\
\hline & Positive & 24 & 22.9 \\
\hline & Negative & 81 & 77.1 \\
\hline \multicolumn{4}{|l|}{ CEA } \\
\hline & $\leqq 3.3$ & 74 & 70.5 \\
\hline & $>3.3$ & 31 & 29.5 \\
\hline \multicolumn{4}{|l|}{ Cyfra21-1 } \\
\hline & $\leqq 3.4$ & 68 & 64.8 \\
\hline & $>3.4$ & 37 & 35.2 \\
\hline \multicolumn{4}{|c|}{ Myelosuppression } \\
\hline & 0 & 30 & 28.6 \\
\hline & I & 40 & 38.1 \\
\hline & II & 25 & 23.8 \\
\hline & III & 8 & 7.6 \\
\hline & IV & 2 & 1.9 \\
\hline
\end{tabular}

$10 \mathrm{~min}$ at $95^{\circ} \mathrm{C}$, followed by $15 \mathrm{~s}$ at $95^{\circ} \mathrm{C}$ and $1 \mathrm{~min}$ at $60^{\circ} \mathrm{C}$ for total 45 cycles.

All samples were run in triplicate. Ct values $\geqq 35$ were considered negative amplification. Differences between the groups are presented as $\Delta \mathrm{Ct}$, indicating the difference between the $\mathrm{Ct}$ value of the miRNA of interest to cel-miR-39 $(\Delta \mathrm{Ct}=$ mean Ct-miRNA - mean Ct-cel- miR-39). Relative gene expression $=2^{-\Delta \Delta \mathrm{Ct}}$, where $-\Delta \Delta \mathrm{Ct}=(\mathrm{Ct}$ gene of interest $-\mathrm{Ct}$ normalized gene $)$ of $(\mathrm{CR}+\mathrm{PR})-(\mathrm{Ct}$ gene of interest $-\mathrm{Ct}$ normalized gene $)$ of $(\mathrm{SD}+\mathrm{PD})[31]$

Statistical analysis. All clinicopathologic variables and circulating miRNA levels were analyzed by using PASW Statistics, Windows software version 17.0 (SPSS, Chicago, IL, USA). An unpaired t-test was performed to compare the differences in serum miRNA levels between groups. Chi-squared test and logistic regression analysis were used to evaluate the association between the levels of miR-24 and clinical-biological variables. All tests were two-sided, and $\mathrm{P}<0.05$ was considered statistically significant.

\section{Results}

Patient characteristics. A total of 105 patients were enrolled from October 2012 to April 2013. As is shown in Table 1, the sex distribution was 69:36 (male:female), with a mean age of 66 years (mean \pm SD age: $66.0 \pm 10.0$ years). There were 30 patients with tumors in the upper third of the esophagus, 60 in the middle, and 15 in the lower third. The length of tumor was $\leqq 4.0 \mathrm{~cm}$ in 53 patients, $4.1-6.0 \mathrm{~cm}$ in 32 patients, and $>6.0 \mathrm{~cm}$ in 20 patients. In terms of tumor differentiation, 24 patients had tumors with high differentiation, 54 moderate differentiation, and 27 poor differentiation. Among the 105 patients, 53 had lymph node metastasis, 80 patients were also found to have distant metastasis. The cut-off values of CYFRA21-1 and CEA were defined as $3.4 \mathrm{ng} \mathrm{ml}^{-1}$ and $3.3 \mathrm{ng}$ $\mathrm{ml}^{-1}$, respectively, according to the $95 \%$ confidence intervals of non-cancer Chinese patients. Levels above the cut-off values were defined as high, while those below the value as low. Therefore, the ESCC patients with lower CYFRA21-1 and CEA were 68 cases and 74 cases, respectively. The control group $(n=30)$ was composed of 17 male and 13 female healthy subjects (mean \pm SD age: $62.0 \pm 9.4$ years). There was no significant difference in age and sex distribution between the patients and the control subjects.

Response to CRT. Of the 105 patients with advanced ESCC enrolled in the study, 5 had CR, 57 had PR, 20 had SD and 23 had PD after concurrent CRT. Because the number of patients achieved CR is low, we combined CR and PR patients as a single "radiosensitive" group. Because the difference between the SD and PD groups are small in terms of tumor burden and metastatic status, we choose to also combine the SD and PD patients as a single "radioresistant" group.

Relative levels of serum miR-24. The result analyses revealed that the $\Delta \mathrm{Ct}$ of serum miR-24 by RT-qPCR was $10.09 \pm 1.53(95 \% \mathrm{CI})$ for the healthy control and $7.82 \pm 1.38$ 

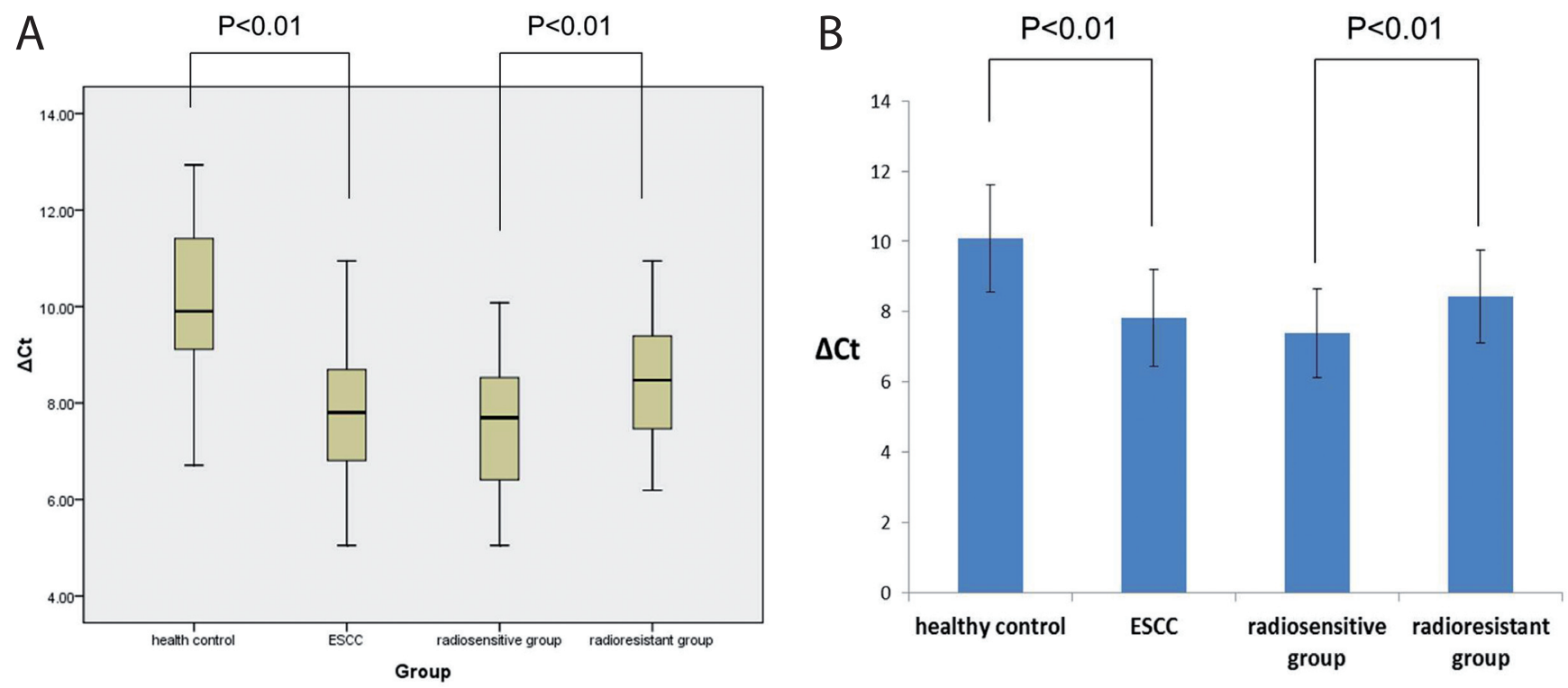

Figure 1. $\Delta$ Ct value of serum miR-24 detected by real-time PCR. (A) box plot; (B) column diagram.

(95\% CI) for the ESCC group, which has been shown in Figure 1. In Figure 1a, we presented the $\Delta \mathrm{Ct}$ value of serum miR-24 by a box plot, meanwhile, Figure $1 \mathrm{~b}$ supplemented it by a column diagram with the mean and the standard deviation. As is shown in Figure 1, the $\Delta \mathrm{Ct}$ of miR-24 expression for the radiosensitive group was $7.39 \pm 1.26(95 \%$ $\mathrm{CI}$ ) and the radioresistant group was $8.43 \pm 1.32(95 \% \mathrm{CI})$. Based on statistical analysis, the relative miR-24 serum level was significantly lower in the $\mathrm{SD}+\mathrm{PD}$ group compared with the $\mathrm{CR}+\mathrm{PR}$ group $(\mathrm{P}<0.05)$. The mean miR-24 serum levels differ by 2.05 folds between these two groups of patients, indicating that it may serve as a biomarker for predicting the response of ESCC patient to CRT. Figure 2 presents the relative expression of serum miR-24 between 2 different groups. As shown by the small range in the present study, the serum miR-24 level in ESCC patients is 4.82 times as high as that in healthy subjects $(\mathrm{P}<0.01)$. The comparison between the healthy subjects and ESCC patients illustrates the possibility that serum miR-24 may also hold the promise as a valuable diagnostic marker.

Relationship between serum miRNA expression and clinicopathological features. In addition to examining the expression of miRNAs in serum, the relationship between miR-24 expression and clinicopathological features of enrolled ESCC patients was examined. By the median value, we demarcated high and low miR-24 levels. As is shown in Table 2, there is no correlation between all clinical-pathological features and miR-24 serum levels.

Moreover, the Table 2 also presents relationships between effectiveness of chemoradiotherapy (CRT) and clinicopathological factors. As is shown in the table, the responsiveness of therapy is significantly correlated with $\mathrm{CEA}(\mathrm{P}<0.05)$,
Cyfra21-1 $(\mathrm{P}<0.05)$, serum miR-24 level $(\mathrm{P}<0.05)$ and the myelosuppression $(\mathrm{P}<0.01)$. Furthermore, by logistic regression analysis, the $\mathrm{CR}+\mathrm{PR}$ rates of $\mathrm{CRT}$ were significantly associated with the levels of Cyfra21-1 $(\mathrm{P}=0.018, \mathrm{OR}=0.253,95 \%$ $\mathrm{CI}$ for $\mathrm{OR}=0.081-0.794), \mathrm{miR}-24(\mathrm{P}=0.011, \mathrm{OR}=0.240,95 \%$ $\mathrm{CI}$ for $\mathrm{OR}=0.079-0.723)$ and myelosuppression $(\mathrm{P}=0.000$, $\mathrm{OR}=3.134,95 \% \mathrm{CI}$ for $\mathrm{OR}=1.677-5.856$ ) before treatments shown in Table 3. That is to say ESCC patients with lower Cyfra21-1, higher miR-24 and severer myelosupression were much more sensitive to CRT.

ROC curve for miR-24. Since our results demonstrated that miR-24 was significantly correlated with ESCC, the ROC curve

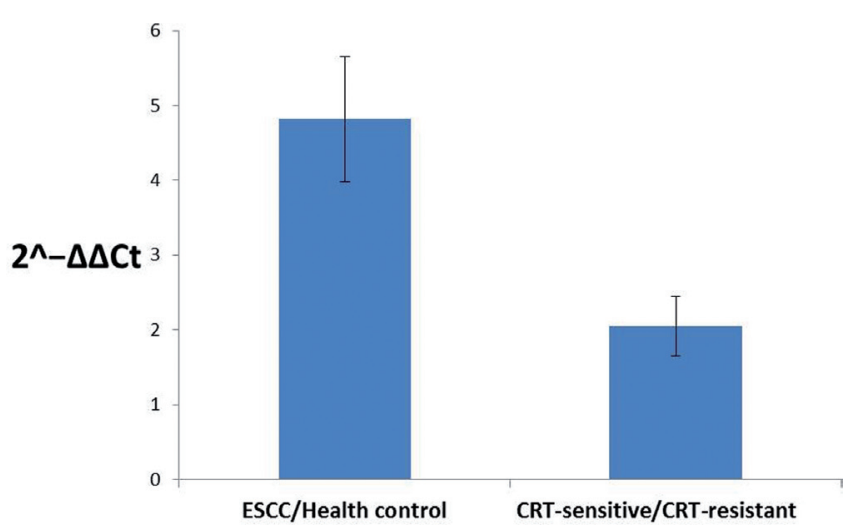

Figure 2. Relative miR-24 expression. Left: the serum miR-24 level in the ESCC patients is 4.82 times as many as that in healthy subjects $(\Delta \Delta \mathrm{Ct}=\Delta \mathrm{Ct}$ of ESCC- $\Delta$ Ct of Health control). Right: the serum miR-24 level in CRTsensitive is 2.05 times as many as that in the CRT-resistant patients $(\Delta \Delta \mathrm{Ct}=\Delta \mathrm{Ct}$ of $(\mathrm{CR}+\mathrm{PR})-\Delta \mathrm{Ct}$ of $(\mathrm{SD}+\mathrm{PD}))$. 
Table 2. Relationships between effectiveness of chemoradiotherapy (CRT) and clinicopathological factors as well as serum levels of tumor markers.

\begin{tabular}{|c|c|c|c|c|c|c|c|c|c|}
\hline \multirow[b]{2}{*}{ Elements } & & \multicolumn{2}{|c|}{ microRNA-24 } & \multirow[b]{2}{*}{$\chi^{2}$} & \multirow[b]{2}{*}{$\mathrm{P}$ value } & \multicolumn{2}{|c|}{ Effectiveness } & \multirow[b]{2}{*}{$\chi^{2}$} & \multirow[b]{2}{*}{$P$ value } \\
\hline & & $\begin{array}{l}\text { High ex- } \\
\text { pression }\end{array}$ & $\begin{array}{l}\text { Low ex- } \\
\text { pression }\end{array}$ & & & $\mathrm{CR}+\mathrm{PR}$ & $\mathrm{SD}+\mathrm{PD}$ & & \\
\hline \multirow[t]{3}{*}{ Sex } & & & & 1.353 & 0.245 & & & 0.012 & 0.914 \\
\hline & Male & 37 & 32 & & & 41 & 28 & & \\
\hline & Female & 15 & 21 & & & 21 & 15 & & \\
\hline \multirow[t]{3}{*}{ Age } & & & & 1.976 & 0.16 & & & 1.155 & 0.282 \\
\hline & $\geqq 60$ & 39 & 33 & & & 40 & 32 & & \\
\hline & $<60$ & 13 & 20 & & & 22 & 11 & & \\
\hline \multirow[t]{4}{*}{ Tumor location } & & & & 0.724 & 0.696 & & & 3.545 & 0.17 \\
\hline & Upper third & 16 & 14 & & & 22 & 8 & & \\
\hline & Middle third & 30 & 30 & & & 32 & 28 & & \\
\hline & Lower third & 6 & 9 & & & 8 & 7 & & \\
\hline \multirow[t]{4}{*}{ Length } & & & & 4.24 & 0.12 & & & 1.662 & 0.436 \\
\hline & $\leqq 4.0$ & 30 & 23 & & & 34 & 19 & & \\
\hline & $4.1-6.0$ & 11 & 21 & & & 16 & 16 & & \\
\hline & $>6.0$ & 11 & 9 & & & 12 & 8 & & \\
\hline \multirow[t]{4}{*}{ Tumor differentiation } & & & & 1.657 & 0.437 & & & 1.557 & 0.459 \\
\hline & High & 10 & 14 & & & 13 & 11 & & \\
\hline & Moderate & 30 & 24 & & & 35 & 19 & & \\
\hline & Poor & 12 & 15 & & & 14 & 13 & & \\
\hline \multirow[t]{3}{*}{ Lymph Node Metastasis } & & & & 0.086 & 0.769 & & & 0.264 & 0.607 \\
\hline & Positive & 27 & 26 & & & 30 & 23 & & \\
\hline & Negative & 25 & 27 & & & 32 & 20 & & \\
\hline \multirow[t]{3}{*}{ Distant Metastasis } & & & & 1.441 & 0.23 & & & 0.012 & 0.912 \\
\hline & Positive & 15 & 10 & & & 15 & 10 & & \\
\hline & Negative & 37 & 43 & & & 47 & 33 & & \\
\hline \multirow[t]{3}{*}{ Smoking History } & & & & 0.234 & 0.628 & & & 0.367 & 0.545 \\
\hline & Positive & 26 & 24 & & & 28 & 22 & & \\
\hline & Negative & 26 & 29 & & & 34 & 21 & & \\
\hline \multirow[t]{3}{*}{ Drinking history } & & & & 0.529 & 0.467 & & & 0.024 & 0.876 \\
\hline & Positive & 18 & 22 & & & 24 & 16 & & \\
\hline & Negative & 34 & 31 & & & 38 & 27 & & \\
\hline \multirow[t]{3}{*}{ Family history } & & & & 0.268 & 0.604 & & & 0.007 & 0.935 \\
\hline & Positive & 13 & 11 & & & 14 & 10 & & \\
\hline & Negative & 39 & 42 & & & 48 & 33 & & \\
\hline \multirow[t]{3}{*}{ CEA } & & & & 1.013 & 0.314 & & & 5.237 & 0.021 \\
\hline & $\leqq 3.3$ & 39 & 35 & & & 49 & 25 & & \\
\hline & $>3.3$ & 13 & 18 & & & 13 & 18 & & \\
\hline \multirow[t]{3}{*}{ Cyfra21-1 } & & & & 0.018 & 0.895 & & & 5.901 & 0.015 \\
\hline & $\leqq 3.4$ & 34 & 34 & & & 46 & 22 & & \\
\hline & $>3.4$ & 18 & 19 & & & 16 & 21 & & \\
\hline Myelosuppression & & & & 0.964 & 0.915 & & & 25.076 & 0.000 \\
\hline & 0 & 13 & 17 & & & 7 & 23 & & \\
\hline & $\mathrm{I}$ & 22 & 18 & & & 26 & 14 & & \\
\hline & II & 12 & 13 & & & 21 & 4 & & \\
\hline & III & 4 & 4 & & & 6 & 2 & & \\
\hline & IV & 1 & 1 & & & 2 & 0 & & \\
\hline MiR-24 level & & & & & & & & 6.244 & 0.012 \\
\hline & Higher level & & & & & 37 & 15 & & \\
\hline & Lower level & & & & & 25 & 28 & & \\
\hline
\end{tabular}


was plotted to identify a cut-off value that could distinguish ESCC from healthy control. ROC curve analysis showed that at the optimal cut-off, serum miR-24 had an $81.9 \%$ sensitivity and an $83.3 \%$ specificity in separating ESCC from normal healthy with an AUC of 0.866 (Figure 3).

\section{Discussion}

CRT play a very critical role in the treatment of esophageal cancer, therefore, many studies have focused on the prediction of treatment responsiveness to CRT. Although TNM stages have been proved to be a key prognostic determinant, large variability in disease outcomes has been observed in ESCC patients with the same stage of disease undergoing similar treatment regimes. Therefore it is important to identify reliable factors that will predict response to CRT, and will also facilitate appropriate patient selection and avoid unnecessary delays in patients at high risk of locoregional recurrence upon chemoradiation [32].

MicroRNA influences carcinogenesis at multiple stages and it can effectively control tumor radiosensitivity by affecting DNA damage repair $[33,34]$, cell cycle checkpoint and apoptosis [35,36], radio-related signal transduction pathways [37] and tumor microenvironment [38]. Understanding the regulatory mechanisms of miRNA in tumor radiosensitivity from these diverse aspects has also become an intensive area of interest. A thorough understanding of tumor radiosensitivity and the regulatory mechanisms of miRNA will not only provide new directions and insights to ultimately improve the radiotherapeutic effect but also bring new hope to more cancer patients [39].

In some previous studies, miR-24 has been characterized as an oncogene in oral carcinoma [26], and lung cancer [27]. While in other studies, it has been proved that miR-24 can

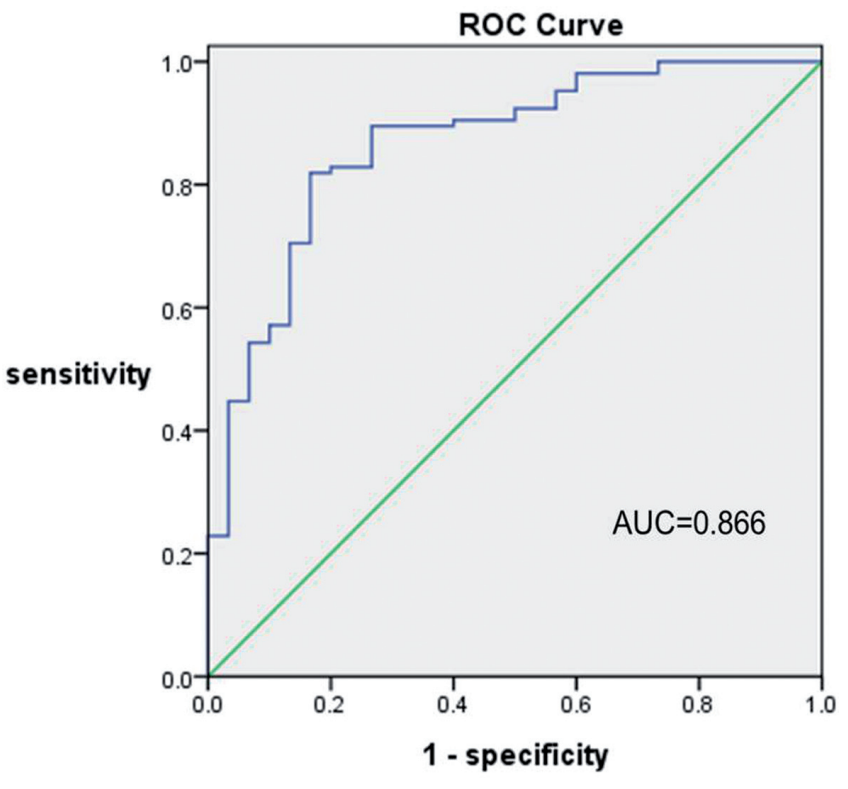

Figure 3. The ROC curve for miR-24. Receiver operating characteristic curve(ROC) analysis was performed to determine the sensitivity and specificity with the value of area under the curve (AUC). In the study, the optimal cut-off $\Delta \mathrm{Ct}$ value for serum miR-24 was 8.93 .

inhibit the initial and progression of cancer cell [24,28,29]. Zaidi[40] reported that expression of miR-24 stimulated myeloid cell growth, rendered proliferation independent of interleukin-3 and blocked granulocytic differentiation. Qin [41] found that miR-24 regulates apoptosis by targeting FAF1 in cancer cells, which also suggested that miR-24 could be an effective drug target for treatment of hormone-insensitive prostate cancer or other types of cancers. In addition, miR-24

Table 3. Multivariate analysis of the clinicopathologic factors related to responsiveness of therapy

\begin{tabular}{|c|c|c|c|c|c|c|c|}
\hline \multirow{2}{*}{ Variables } & \multirow{2}{*}{ B } & \multirow{2}{*}{ S.E. } & \multirow{2}{*}{ Wals } & \multirow{2}{*}{$P$ value } & \multirow{2}{*}{ OR } & \multicolumn{2}{|c|}{ 95\% C.I. For OR } \\
\hline & & & & & & Lower & Upper \\
\hline Sex & 0.377 & 0.765 & 0.243 & 0.622 & 1.458 & 0.325 & 6.537 \\
\hline Age & 0.698 & 0.572 & 1.487 & 0.223 & 2.009 & 0.655 & 6.166 \\
\hline Lymph Node Metastasis & -0.485 & 0.565 & 0.739 & 0.390 & 0.615 & 0.204 & 1.861 \\
\hline Distant Metastasis & 0.417 & 0.705 & 0.350 & 0.554 & 1.518 & 0.381 & 6.043 \\
\hline Tumor location & -0.205 & 0.423 & 0.234 & 0.628 & 0.815 & 0.356 & 1.867 \\
\hline Length & -0.180 & 0.349 & 0.265 & 0.607 & 0.836 & 0.422 & 1.656 \\
\hline Tumor differentiation & 0.218 & 0.359 & 0.368 & 0.544 & 1.243 & 0.615 & 2.512 \\
\hline Smoking History & 0.233 & 0.731 & 0.102 & 0.750 & 1.263 & 0.302 & 5.287 \\
\hline Drinking history & -0.374 & 0.694 & 0.290 & 0.590 & 0.688 & 0.177 & 2.684 \\
\hline Family history & -0.079 & 0.633 & 0.016 & 0.901 & 0.924 & 0.267 & 3.196 \\
\hline Myelosuppression & 1.142 & 0.319 & 12.826 & 0.000 & 3.134 & 1.677 & 5.856 \\
\hline CEA & -1.127 & 0.579 & 3.789 & 0.052 & 0.324 & 0.104 & 1.008 \\
\hline Cyfra21-1 & -1.374 & 0.583 & 5.553 & 0.018 & 0.253 & 0.081 & 0.794 \\
\hline MiR-24 level & -1.429 & 0.564 & 6.429 & 0.011 & 0.240 & 0.079 & 0.723 \\
\hline Constant & 4.075 & 2.462 & 2.740 & 0.098 & 58.879 & & \\
\hline
\end{tabular}


functioned in DNA Damage Repair(DDR), For example, when DNA double-strand damage occurs, miR-24 reduces genomic stability and DNA damage repair ability by regulating $\mathrm{H} 2 \mathrm{AX}$ expression [23]. Moreover, miR-24-mediated downregulation of H2AX increases cell death after DNA damage.

The present study showed that serum miR-24 levels were up-regulated (4.82-fold change) in patients with ESCC compared with healthy controls, indicating it may be a useful biomarker for early diagnosis. This suggested a role of miR-24 in tumorigenesis and development, which was consistent with previous studies showing that miR-24 was highly expressed in patients with gastric cancer and lung cancer [42], cervical cancer [43]. ROC curve analysis showed that at the optimal cut-off, serum miR-24 had an $81.9 \%$ sensitivity and an $83.3 \%$ specificity in separating ESCC from normal healthy with an AUC of 0.866 (Figure 3). Such findings imply that miR-24 might be involved in the initiation and progression of cancer. Since the sampling of blood is relative non-invasive, our results would seem to support the potential of using serum miR -24 as an ESCC biomarker.

In the result, we analyze the relationship between serum miR-24 and clinical features. Unfortunately, we didn't find any factor can influence serum miR-24 level including tumor length, lymph node staus, and so on. This was partly because most of the patients enrolled were at an advanced stage and the sample was relatively small. However, further largescale studies will be required for a final conclusion.

Furthermore, the expression level analysis revealed that serum miR-24 is a valuable biomarker for differentiating the responsiveness to CRT of ESCC patients. As is shown in the Table 2, the responsiveness to CRT were significantly associated with the levels of Cyfra21-1, CEA, miR-24 and myelosuppression before treatments. While as is shown in Table 3, ESCC patients with lower Cyfra21-1, higher miR-24, and severer myelosupression were much more sensitive to CRT, which is similar to previous studies [44-46]. However, this conclusion should be confirmed by study of larger and more homogeneous samples.

In conclusion, the present study showed that serum miR24 levels were significantly higher in patients with ESCC compared with control subjects. ESCC patients with lower Cyfra21-1, higher miR-24, and severer myelosupression were much more sensitive to CRT. These findings indicate that serum miR-24 may serve as a novel diagnostic and response predictive marker for ESCC.

Acknowledgments: This work was supported in part by 2011GGC03054 from Science and Technology Project of Shandong Province.

\section{References}

[1] JEMAL A, BRAY F, CENTER MM, FERLAY J, WARD E, et al. Global cancer statistics. CA: a cancer journal for clinicians 2011; 61: 69-90. http://dx.doi.org/10.3322/caac.20107
[2] SCHNEIDER BJ URBA SG. Preoperative chemoradiation for the treatment of locoregional esophageal cancer: The standard of care? Seminars in radiation oncology 2007; 17: 45-52. http://dx.doi.org/10.1016/j.semradonc.2006.09.002

[3] SHIBATA T, KOKUBU A, SAITO S, NARISAWA-SAITO $\mathrm{M}$, SASAKI $\mathrm{H}$, et al. Nrf2 mutation confers malignant potential and resistance to chemoradiation therapy in advanced esophageal squamous cancer. Neoplasia 2011; 13: 864-873.

[4] LUTHRA R, WU TT, LUTHRA MG, IZZO J, LOPEZALVAREZ E, et al. Gene expression profiling of localized esophageal carcinomas: Association with pathologic response to preoperative chemoradiation. Journal of clinical oncology : official journal of the American Society of Clinical Oncology 2006; 24: 259-267. http://dx.doi.org/10.1200/ LCO.2005.03.3688

[5] WU X, GU J, WU TT, SWISHER SG, LIAO Z, et al. Genetic variations in radiation and chemotherapy drug action pathways predict clinical outcomes in esophageal cancer. Journal of clinical oncology : official journal of the American Society of Clinical Oncology 2006; 24: 3789-3798. http://dx.doi. org/10.1200/JCO.2005.03.6640

[6] EDGE SB COMPTON CC. The american joint committee on cancer: The 7th edition of the ajcc cancer staging manual and the future of tnm. Annals of surgical oncology 2010;17: 1471-1474. http://dx.doi.org/10.1245/s10434-010-0985-4

[7] LIU N, CUI RX, SUN Y, GUO R, MAO YP, et al. A four-mirna signature identified from genome-wide serum mirna profiling predicts survival in patients with nasopharyngeal carcinoma. International journal of cancer. Journal international du cancer 2013.

[8] ZHANG JX, TONG ZT, YANG L, WANG F, CHAI HP, et al. Pitx2: A promising predictive biomarker of patients' prognosis and chemoradioresistance in esophageal squamous cell carcinoma. International journal of cancer. Journal international du cancer 2013; 132: 2567-2577. http://dx.doi.org/10.1002/ ijc. 27930

[9] ESQUELA-KERSCHER A SLACK FJ. Oncomirs - micrornas with a role in cancer. Nature reviews. Cancer 2006; 6: 259-269. http://dx.doi.org/10.1038/nrc1840

[10] BLANDINO G, FAZI F, DONZELLI S, KEDMI M, SASCHEN A, et al. Tumor suppressor micrornas: A novel non-coding alliance against cancer. FEBS letters 2014. http:// dx.doi.org/10.1016/j.febslet.2014.03.033

[11] BOUYSSOU JM, MANIER S, HUYNH D, ISSA S, ROCCARO $\mathrm{AM}$, et al. Regulation of micrornas in cancer metastasis. Biochim Biophys Acta 2014; 1845: 255-265.

[12] WESTERMANN AM, SCHMIDT D, HOLDENRIEDER S, MORITZ R, SEMJONOW A, et al. Serum micrornas as biomarkers in patients undergoing prostate biopsy: Results from a prospective multi-center study. Anticancer research 2014; 34: 665-669.

[13] DIAO Y, GUO X, JIANG L, WANG G, ZHANG C, et al. Mir-203, a tumor suppressor frequently down-regulated by promoter hypermethylation in rhabdomyosarcoma. The Journal of biological chemistry 2014; 289: 529-539. http:// dx.doi.org/10.1074/jbc.M113.494716 
[14] MENENDEZ P, PADILLA D, VILLAREJO P, PALOMINO T, NIETO P, et al. Prognostic implications of serum microrna-21 in colorectal cancer. Journal of surgical oncology 2013; 108: 369-373. http://dx.doi.org/10.1002/jso.23415

[15] ZHAO S, YAO D, CHEN J DING N. Circulating mirna20a and mirna-203 for screening lymph node metastasis in early stage cervical cancer. Genetic testing and molecular biomarkers 2013; 17: 631-636. http://dx.doi.org/10.1089/ gtmb.2013.0085

[16] KOBAYASHI E, HORNICEK FJ DUAN Z. Microrna involvement in osteosarcoma. Sarcoma 2012; 2012: 359739.

[17] LI ZH, ZHANG H, YANG ZG, WEN GQ, CUI YB, et al. Prognostic significance of serum microrna-210 levels in nonsmall-cell lung cancer. The Journal of international medical research 2013.

[18] MITCHELL PS, PARKIN RK, KROH EM, FRITZ BR, WYMAN SK, et al. Circulating micrornas as stable bloodbased markers for cancer detection. Proceedings of the National Academy of Sciences of the United States of America 2008; 105: 10513-10518. http://dx.doi.org/10.1073/ pnas.0804549105

[19] KROH EM, PARKIN RK, MITCHELL PS TEWARI M. Analysis of circulating microrna biomarkers in plasma and serum using quantitative reverse transcription-pcr (qrt-pcr). Methods 2010; 50: 298-301. http://dx.doi.org/10.1016/j. ymeth.2010.01.032

[20] QIAN L, VAN LAAKE LW, HUANG Y, LIU S, WENDLAND MF, et al. Mir-24 inhibits apoptosis and represses bim in mouse cardiomyocytes. The Journal of experimental medicine 2011; 208: 549-560. http://dx.doi.org/10.1084/ jem.20101547

[21] WANG Q, HUANG Z, XUE H, JIN C, JU XL, et al. Microrna mir-24 inhibits erythropoiesis by targeting activin type i receptor alk4. Blood 2008; 111: 588-595. http://dx.doi.org/10.1182/ blood-2007-05-092718

[22] LAL A, KIM HH, ABDELMOHSEN K, KUWANO Y, PULLMANN R, JR., et al. P16(ink4a) translation suppressed by mir-24. PloS one 2008; 3: e1864.

[23] LAL A, PAN Y, NAVARRO F, DYKXHOORN DM, MOREAU L, et al. Mir-24-mediated downregulation of h2ax suppresses DNA repair in terminally differentiated blood cells. Nature structural \& molecular biology 2009; 16: 492-498. http:// dx.doi.org/10.1038/nsmb.1589

[24] LAL A, NAVARRO F, MAHER CA, MALISZEWSKI LE, YAN N, et al. Mir-24 inhibits cell proliferation by targeting e2f2, myc, and other cell-cycle genes via binding to "seedless" 3'utr microrna recognition elements. Molecular cell 2009; 35: 610-625. http://dx.doi.org/10.1016/j. molcel.2009.08.020

[25] <152624dsz.Pdf $>$.

[26] LIN SC, LIU CJ, LIN JA, CHIANG WF, HUNG PS, et al. Mir24 up-regulation in oral carcinoma: Positive association from clinical and in vitro analysis. Oral oncology 2010; 46: 204-208. http://dx.doi.org/10.1016/j.oraloncology.2009.12.005

[27] CAO M, SEIKE M, SOENO C, MIZUTANI H, KITAMURA $\mathrm{K}$, et al. Mir-23a regulates tgf-beta-induced epithelialmesenchymal transition by targeting e-cadherin in lung cancer cells. International journal of oncology 2012; 41: 869-875.

[28] TO KH, PAJOVIC S, GALLIE BL THERIAULT BL. Regulation of p14arf expression by mir-24: A potential mechanism compromising the 553 response during retinoblastoma development. BMC cancer 2012; 12: 69. http:// dx.doi.org/10.1186/1471-2407-12-69

[29] MISHRA PJ, SONG B, MISHRA PJ, WANG Y, HUMENIUK $\mathrm{R}$, et al. Mir-24 tumor suppressor activity is regulated independent of p53 and through a target site polymorphism. PloS one 2009; 4: e8445. http://dx.doi.org/10.1371/journal. pone. 0008445

[30] MILLER AB, HOOGSTRATEN B, STAQUET M WINKLER A. Reporting results of cancer treatment. Cancer 1981; 47: 207-214. http://dx.doi.org/10.1002/1097-0142(19810101)47: 1<207: : AID-CNCR2820470134>3.0.CO; 2-6

[31] SCHMITTGEN TD, LEE EJ JIANG J. High-throughput realtime pcr. Methods in molecular biology 2008; 429: 89-98. http://dx.doi.org/10.1007/978-1-60327-040-3 7

[32] FOKAS E, WEISS C RODEL C. The role of radiotherapy in the multimodal management of esophageal cancer. Digestive diseases 2013; 31: 30-37. http://dx.doi.org/10.1159/000347170

[33] HU H GATTI RA. Micrornas: New players in the DNA damage response. J Mol Cell Biol 2011; 3: 151-158. http://dx.doi. org/10.1093/jmcb/mjq042

[34] LANDAU DA SLACK FJ. Micrornas in mutagenesis, genomic instability, and DNA repair. Seminars in oncology 2011; 38: 743-751. http://dx.doi.org/10.1053/j. seminoncol.2011.08.003

[35] YANG X, FENG M, JIANG X, WU Z, LI Z, et al. Mir$449 \mathrm{a}$ and mir-449b are direct transcriptional targets of e2f1 and negatively regulate prb-e2f1 activity through a feedback loop by targeting cdk6 and cdc25a. Genes \& development 2009; 23: 2388-2393. http://dx.doi.org/10.1101/ gad.1819009

[36] LEGESSE-MILLER A, ELEMENTO O, PFAU SJ, FORMAN JJ, TAVAZOIE S, et al. Let-7 overexpression leads to an increased fraction of cells in $\mathrm{g} 2 / \mathrm{m}$, direct down-regulation of cdc34, and stabilization of wee1 kinase in primary fibroblasts. The Journal of biological chemistry 2009; 284: 6605-6609. http://dx.doi. org/10.1074/jbc.C900002200

[37] LIM WK MICKLEM G. Micrornas dysregulated in breast cancer preferentially target key oncogenic pathways. Molecular bioSystems 2011; 7: 2571-2576. http://dx.doi.org/10.1039/ c1mb05181d

[38] YAMAKUCHI M, YAGI S, ITO T LOWENSTEIN CJ. Microrna-22 regulates hypoxia signaling in colon cancer cells. PloS one 2011; 6: e20291. http://dx.doi.org/10.1371/journal. pone.0020291

[39] ZHAO L, BODE AM, CAO Y DONG Z. Regulatory mechanisms and clinical perspectives of mirna in tumor radiosensitivity. Carcinogenesis 2012; 33: 2220-2227. http:// dx.doi.org/10.1093/carcin/bgs235

[40] ZAIDI SK, DOWDY CR, VAN WIJNEN AJ, LIAN JB, RAZA $A$, et al. Altered runx1 subnuclear targeting enhances myeloid cell proliferation and blocks differentiation by activating a mir-24/mkp-7/mapk network. Cancer research 2009; 69: 
8249-8255. http://dx.doi.org/10.1158/0008-5472.CAN-09$\underline{1567}$

[41] QIN W, SHI Y, ZHAO B, YAO C, JIN L, et al. Mir-24 regulates apoptosis by targeting the open reading frame (orf) region of faf1 in cancer cells. PloS one 2010; 5: e9429. http://dx.doi. org/10.1371/journal.pone.0009429

[42] XIE L, WANG T, YU S, CHEN X, WANG L, et al. Cell-free mir-24 and mir-30d, potential diagnostic biomarkers in malignant effusions. Clinical biochemistry 2011; 44: 216-220. http://dx.doi.org/10.1016/j.clinbiochem.2010.11.002

[43] WANG X, TANG S, LE SY, LU R, RADER JS, et al. Aberrant expression of oncogenic and tumor-suppressive micrornas in cervical cancer is required for cancer cell growth. PloS one 2008; 3: e2557. http://dx.doi.org/10.1371/journal.pone.0002557
[44] KUNISAKI C, IMADA T, YAMADA R, HATORI S, KINBARA K, et al. Prognostic factors after chemoradiotherapy for patients with inoperable esophageal squamous cell carcinoma. Hepato-gastroenterology 2006; 53: 366-371.

[45] WAKATSUKI M, SUZUKI Y, NAKAMOTO S, OHNO T, ISHIKAWA $\mathrm{H}$, et al. Clinical usefulness of cyfra 21-1 for esophageal squamous cell carcinoma in radiation therapy. Journal of gastroenterology and hepatology 2007; 22: 715-719.

[46] YI Y, LI B, WANG Z, SUN H, GONG H, et al. Cyfra21-1 and cea are useful markers for predicting the sensitivity to chemoradiotherapy of esophageal squamous cell carcinoma. Biomarkers : biochemical indicators of exposure, response, and susceptibility to chemicals $2009 ; 14: 480-485$. http:// dx.doi.org/10.3109/13547500903180265 